\title{
ON THE REGULATION OF DISSOLVED OXYGEN BY NEPENTHES PITCHERS
}

KadeEm J. Gilbert - Museum of Comparative Zoology - Harvard University - Cambridge

- Massachusetts - USA • and - Department of Entomology • Pennsylvania State University

- State College • Pennsylvania・USA・kjg5649@psu.edu

Keywords: Nepenthes, pitcher plants, dissolved oxygen levels, pitcher fluid regulation, phytotelmata.

Abstract: The digestive fluid of tropical pitcher plants (Nepenthaceae: Nepenthes L.) typically harbor communities of symbiotic organisms in nature, an example of a phytotelm ecosystem. While the inhabitants of pitchers (primarily the arthropods) have been described and studied from a community ecology perspective for over a century, many abiotic properties of the fluid environment have not been thoroughly documented. As the abiotic properties of the pitcher fluid micro-environment may have fitness and/or functional consequences on the inhabitants, it is of interest to examine intraand interspecific variation in fluid properties. Here I report observations of dissolved oxygen levels in Nepenthes pitchers. I find evidence that Nepenthes pitchers actively modify dissolved oxygen levels in the fluid and that this oxygenation ability may vary ontogenetically, with relatively hypoxic conditions in newly opened pitchers and high oxygen levels maintained in more mature pitchers.

\section{Introduction}

Most phytotelmata (plant-held aquatic microhabitats) are ephemeral resources prone to desiccation and hypoxia (Kitching 2001). Communities of heterotrophic organisms living within waterfilled tree holes or bromeliad tanks, for example, can easily deplete the oxygen dissolved in the water unless photosynthetic algae are also present, as the host plant tissues lack the ability to actively maintain the dissolved oxygen (DO) of their phytotelm (Laessle 1961). Pitcher plants, on the other hand, can actively maintain DO. Past studies demonstrated that Sarracenia pitchers normally maintain high DO even with communities dominated by heterotrophic inquilines (Cameron et al. 1977; Bradshaw 1983). Sarracenia pitchers contain chloroplasts in the epidermal cells of the pitcher interior, which is unusual as this is non-stomatal tissue that would typically lack chloroplasts in terrestrial plant species (Joel \& Gepstein 1985). Bradshaw (1983) demonstrated that Sarracenia (Sarraceniaceae) pitchers assimilate dissolved $\mathrm{CO}_{2}$ in the presence of light while maintaining stable DO without much regard to light. The oxygenation of pitcher fluid by the host plant allows the survival of the highly oxygen-sensitive Metriocnemus knabi (Cameron et al. 1977), an obligately associated chironomid midge, which benefits the host Sarracenia purpurea by aiding in prey digestion (Heard 1994). Thus, fluid oxygenation seems to have an important role in enabling this mutualistic association. On the other hand, dissolved oxygen levels in the pitchers of the convergently evolved Old World tropical pitcher plants (Nepenthaceae: Nepenthes) have not been described in published reports, to my knowledge. Studies on the photosynthetic efficiency of Nepenthes pitchers and laminae for four species ( $N$. talangensis, $N$. alata, $N$. mirabilis, and $N$. ventricosa) showed that pitchers exhibit relatively low net assimilation rates (Pavlovič et al. 2007, 2009; Adamec 2010). That the functions of digestion and photosynthesis are carried out by two distinct organs in Nepenthes as opposed to the dual role of the pitchers of the Sarraceniaceae presents an interesting complication when trying to draw parallels between what was shown for Sarracenia and what may be the case in 
Nepenthes. Relative to Sarracenia, Nepenthes pitchers do not have as much photosynthetic tissue, but there are increased chloroplasts in the digestive zone, surrounding the glands (Pavlovič et al. 2007). Thus, I sought to determine whether Nepenthes pitchers oxygenate their fluid as has been shown for Sarracenia. I was interested in whether there might be species and/or ontogenetic differences in pitcher fluid oxygenation. Here I present my observations of oxygen levels in Nepenthes pitchers from various natural and experimental contexts.

\section{Materials and Methods}

In July-September 2013, I conducted exploratory investigations of oxygenation in Nepenthes using 3 small potted individuals each of N. maxima, N. albomarginata, and N. ampullaria (Black Jungle Terrarium Supply), reared in a growth chamber in Cambridge, Massachusetts (12 hour day/ night cycle, $80 \%$ relative humidity, $30^{\circ} \mathrm{C}$ ). To examine whether pitchers can manipulate oxygen levels in the absence of inquiline communities, I added distilled deionized water $\left(\mathrm{ddH}_{2} \mathrm{O}\right)$ to pitchers which I had emptied and washed out (removing any prey items). Drawing up $1 \mathrm{~mL}$ water samples into a Luer-Lok syringe, carefully so as to prevent agitation and aeration of the sample, I then measured DO concentration in the samples using the Shriwastav et al. (2010) micro-Winkler titration method (110 samples). The Shriwastav et al. (2010) method is a modification of a standard technique for measuring DO in limnological studies, which was adapted for measuring small samples. The sample is kept under a layer of n-hexane before fixing in order to prevent atmospheric $\mathrm{O}_{2}$ contamination. The sample is fixed with $5 \mu \mathrm{L}$ each of $\mathrm{MnSO}_{4}$ and alkali-azide-iodate solution; next the resulting precipitate is dissolved with $0.1 \mathrm{~mL} \mathrm{H}_{2} \mathrm{SO}_{4}$, and then finally the resulting iodine solution is stained with starch indicator and titrated with sodium thiosulfate until clear. I also measured oxygen levels from $\mathrm{ddH}_{2} \mathrm{O}$ in glass containers with this method (22 samples) and also measured DO in the endogenous fluid from pitchers that had just opened one or two days prior ( 7 samples). For the majority of measurements in this experiment, I collected and fixed the sample for titration within 24 hours of adding the $\mathrm{ddH}_{2} \mathrm{O}$, but in a few cases I measured DO in pitchers/glass containers after letting the $\mathrm{ddH}_{2} \mathrm{O}$ sit for $\sim 1$ week (10 samples, including 2 from glass containers) or $\sim 1$ month (14 samples, 3 from glass) after its addition. For statistical analysis, I conducted linear mixed models in R 3.5.0 (RCoreTeam 2013) using the 'Imer' function in the 'Ime4' package (Bates et al. 2015) and including plant/pitcher ID as a random effect to account for multiple sampling and correct for pseudoreplication.

In January 2014, I took opportunistic measurements of dissolved oxygen levels in unopened pitchers of wild Nepenthes gracilis in Kent Ridge Park, Singapore using the Shriwastav et al. (2010) micro-Winkler titration method. I sampled fluid from 10 unopened pitchers, but as many of these had fluid volumes less than $1 \mathrm{~mL}$, I had to pool them, which resulted in 5 samples for titration.

In August 2014, I measured dissolved oxygen concentrations in Nepenthes pitchers in a Singapore horticultural glasshouse (HortPark Nepenthes nursery; plants sourced from Borneo Exotics Ltd.) with a well-regulated indoor environment $\left(16^{\circ} \mathrm{C}\right.$ temperature, $80 \%$ relative humidity). I used a fiber-optic probe and spectrometer-based sensing system (Ocean Optics, Inc., Dunedin, Florida, USA). The probe was calibrated on-site using saturated and deoxygenated $\mathrm{dd}_{2} \mathrm{O}$ standards. Pitchers were covered with a dark opaque fabric during measurements to mitigate noisy measurements that could occur due to ambient light. I recorded point measurements taken from the middle of the fluid column; I made sure to keep the probe in the same relative position for each measurement as I had observed possible differences in oxygen level depending on the depth of the probe within individual pitchers. 
In February 2016, I collected fluid from several wild $N$. gracilis in Kent Ridge Park in Singapore, homogenized and filtered that fluid in a sterile bottle-top vacuum filter, and added $1.0 \mathrm{~mL}$ allotments of this stock fluid to open glass vials (with similar dimensions to $N$. gracilis pitchers) and healthy mature pitchers from potted $N$. gracilis plants that I had emptied out and washed beforehand. Each vial or pitcher also received an equal-sized mealworm segment and each container type was equally divided into four treatments: one mosquito (Diptera: Culicidae, either Culex or Tripteroides) larva added, one Endonepenthia (Diptera: Phoridae) larva added, a combination of one mosquito and one Endonepenthia larva added, and no larvae added. I measured oxygen levels with an oxygen optrode (Ocean Optics) after about 18 hours. This experiment was conducted in a greenhouse at the Raffles Institution, with the original goal of observing the effects of inquilines on pitcher ammonia levels, but this experiment incidentally worked well for studying DO.

\section{Results and Discussion}

My observations from the N. maxima, N. albomarginata, and N. ampullaria in the growth chamber provide some insight into the possibility that dissolved oxygen in pitchers is influenced by plant physiology, which is seen primarily in age-dependent differences in DO levels (Fig. 1). Pitcher age/ condition has a significant effect on the DO of the experimentally added $\mathrm{ddH}_{2} \mathrm{O}$, specifically, in reference to mature pitchers, newly opened pitchers tend to have lower DO (correlation estimate $=$
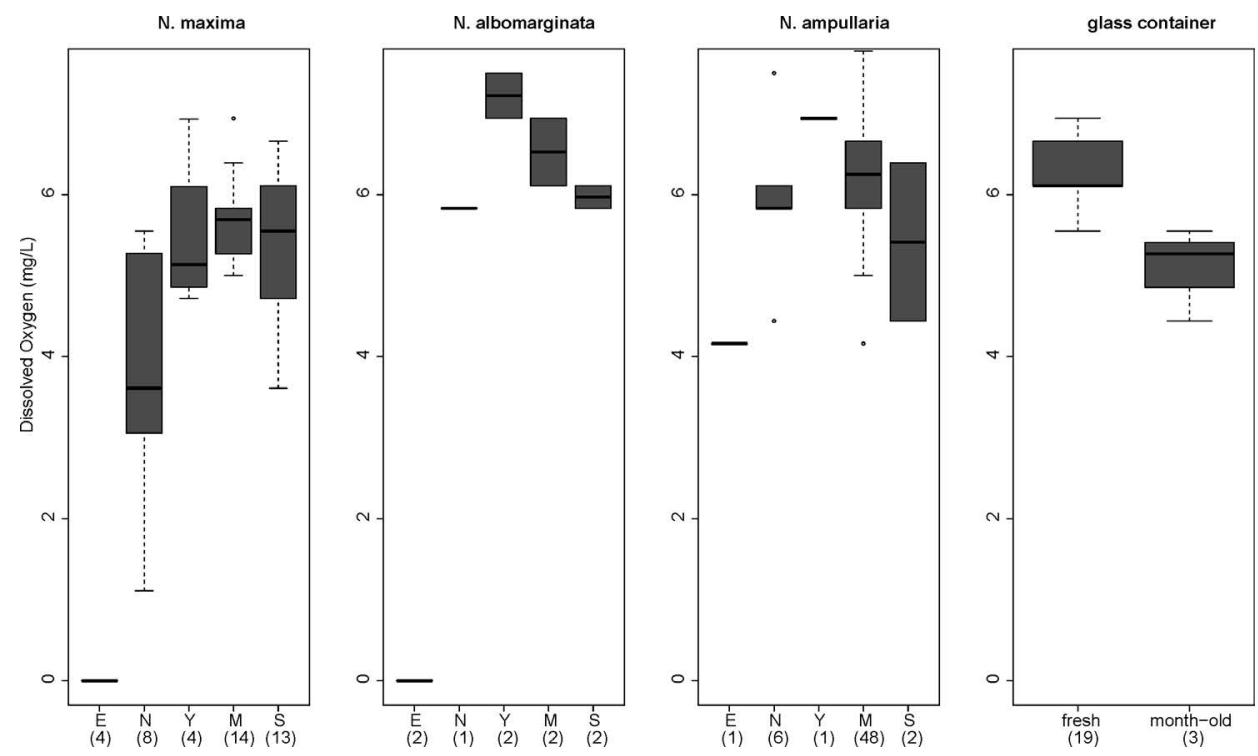

Figure 1: Results of 2013 growth chamber study, dissolved oxygen levels for the three Nepenthes species are broken down by pitcher age/condition, where $\mathrm{E}=$ endogenouslyproduced fluid in newly-opened (1-2 days post-opening) pitchers, $\mathrm{N}=$ "newly-opened" (<1 week post-opening) pitchers, $Y=$ "young" ( 2 weeks post-opening), $M=$ "mature" (>2 weeks post-opening) pitchers, and $S$ = "senescent" (brown/dying/dead) pitchers. For glass containers, "fresh" refers to $\mathrm{dd}_{2} \mathrm{O}$ DO measured less than one week after addition, and "month-old" refers to $\mathrm{ddH}_{2} \mathrm{O}$ DO measured about one month after addition. Sample sizes for each pitcher condition or treatment is given underneath in parentheses. 
$-1.14, \mathrm{p}=0.0006)$, and likewise the endogenous fluid of newly opened pitchers has exceptionally low DO (correlation estimate $=-5.41, \mathrm{p}<<0.0001$ ); senescent (browning/dead) pitchers have a slight, nonsignificant trend towards lower DO (correlation estimate $=-0.53, \mathrm{p}=0.08$ ), and young pitchers are not significantly different (correlation estimate $=0.20, p=0.62$ ). On the other hand, variation in DO levels cannot be explained by letting the water sit for different periods of time ( $\mathrm{p}=$ 0.47 and 0.85 for week-long and month-long waiting period, respectively). The observations within these alternative waiting periods still vary according to the pitcher condition: for example, of the week-long waiting period samples, the DO of the 3 mature pitchers average $6.29 \mathrm{mg} / \mathrm{L}$ while DO of the 2 newly opened pitchers average $3.47 \mathrm{mg} / \mathrm{L}$. Note that fully saturated water (i.e. water with $21 \%$ $\mathrm{O}_{2}$ ) would hold an estimated $7.55 \mathrm{mg} / \mathrm{L}$ at $30^{\circ} \mathrm{C}$ or $8.26 \mathrm{mg} / \mathrm{L}$ at room temperature.

For glass containers, while not statistically significant (two sample t-test, $\mathrm{t}=3.33, \mathrm{p}=0.06$ ), month-old $\mathrm{ddH}_{2} \mathrm{O}$ samples clearly reach lower DO levels than those taken from more freshly added $\mathrm{ddH}_{2} \mathrm{O}$ examined no longer than a week after addition. The fresh $\mathrm{ddH}_{2} \mathrm{O}$ in glass containers serves as a baseline for unmanipulated $\mathrm{ddH}_{2} \mathrm{O}$ DO levels and the observations of month-old $\mathrm{ddH}_{2} \mathrm{O}$ in glass shows that it takes at least a month for neutral processes (e.g. evaporation, microbial respiration) to drive down the DO in this context, and even then, it did not reach any lower than $4.44 \mathrm{mg} / \mathrm{L}$. Thus, it is especially surprising that in less than 24 hours, $\mathrm{ddH}_{2} \mathrm{O}$ added to certain pitchers can reach much lower levels than that (as low as 4.27 and $1.11 \mathrm{mg} / \mathrm{L}$ in senescent and new pitchers, respectively).

What I had expected prior to this study was that living pitchers would oxygenate their fluid and have higher DO than senescent pitchers, but what I found instead is that the youngest pitchers seem capable of rapidly deoxygenating their fluid, while older pitchers (whether healthy or senescent) stay within the normal DO levels seen in the glass controls during the short waiting period scheme. As pitchers in this experimental design were void of any insect inquilines and likely void of substantial microbial communities that could drive down DO with respiration, it is not possible to discern from this whether fluid oxygenation switches on in young/mature pitchers and then turns off in senescent ones - of note however, the sole month-old $\mathrm{ddH}_{2} \mathrm{O}$ sample from a senescent pitcher reached the markedly low DO level of $3.61 \mathrm{mg} / \mathrm{L}$ while the month-old samples from healthy mature pitchers averaged $5.97 \mathrm{mg} / \mathrm{L}$. While not conclusive due to small sample sizes, this is consistent with senescent pitchers acting more like inert containers and healthy pitchers actively maintaining higher DO levels over time. More conclusive here is the occurrence of active deoxygenation in newly opened pitchers. The pattern is best seen in N. maxima, which had the most even sampling, but the pattern of relatively lower DO in new pitchers can still be seen in the other two species (Fig. 1).

The most striking finding, alongside the hypoxic conditions in newly opened pitchers, is that the endogenous fluid within newly opened pitchers appears to be anoxic $(0 \mathrm{mg} / \mathrm{L})$ in all observations from $N$. maxima (4 samples) and $N$. albomarginata ( 2 samples). My one observation of endogenous fluid from a newly opened pitcher of $N$. ampullaria still followed the pattern of endogenous fluid having the relatively lowest DO within a species, but in this case, it was merely hypoxic at $4.16 \mathrm{mg} / \mathrm{L}$.

Overall, DO did not vary significantly by species in this study (linear mixed model, $\mathrm{p}>0.4$ for each species). However, when comparing just the mature pitchers of N. ampullaria and N. maxima (no significant differences between either species and $N$. albomarginata, which has a very low sample size), $N$. ampullaria is found to have significantly higher mean DO here (t-test, $\mathrm{t}=3.06$, $\mathrm{p}=0.005): 6.26 \mathrm{mg} / \mathrm{L}$ compared to $N$. maxima's $5.69 \mathrm{mg} / \mathrm{L}$. While I cannot firmly conclude from this that pitcher oxygenation is a trait that varies interspecifically across the genus, it could make sense for species that evolved specialized dietary strategies like N. ampullaria (Moran et al. 2003) to regulate their fluid properties in different ways. For instance, $N$. ampullaria is known to maintain milder $\mathrm{pH}$ levels compared to other species, which is believed to create a more permissive environ- 
ment for the diverse community of insect inquilines that may help break down captured leaf litter (Moran et al. 2010). Similarly, maintaining oxygen-rich fluid could help sustain more inquilines. Perhaps the higher DO in the endogenous pitcher fluid of newly opened N. ampullaria compared to the anoxic fluids of the other two species indicates that $N$. ampullaria oxygenates more at all stages (as a caveat: it was more difficult to catch the exact moment of pitcher opening due to the uniquely narrow lid of this species, so that pitcher may have been open relatively longer before sampling than the other species).

Looking further into the potential of interspecific variation in pitcher oxygenation, I obtained data from 12 Nepenthes species and hybrids in the HortPark glasshouse in 2014: N. chaniana $\times$ veitchii, $N$. clipeata $\times$ eymae, $N$. copelandii, $N$. densiflora, $N$. fusca, $N$. inermis $\times$ bongso, $N$. jamban, $N$. khasiana, $N$. muluensis $\times$ lowii, $N$. sanguinea, $N$. spectabilis $\times$ talangensis, and N. tentaculatathough sample sizes within each species were generally low (Fig. 2). I did not find significant differences in dissolved oxygen concentrations by species (Kruskal-Wallis chi-squared $=14.124, \mathrm{p}=$ 0.23 ), but there was notable variation across all pitchers, ranging from $\sim 5 \%$ to $\sim 30 \%$ oxygen (where atmospheric oxygen in the greenhouse was $21 \%$ ).

I noticed a possible trend of upper pitchers having smaller DO values than lower pitchers (Fig. 3). Most species did not have multiple pitcher morphs available, and in most cases, there either was not a significant difference or enough replication to be meaningful. However, I obtained several

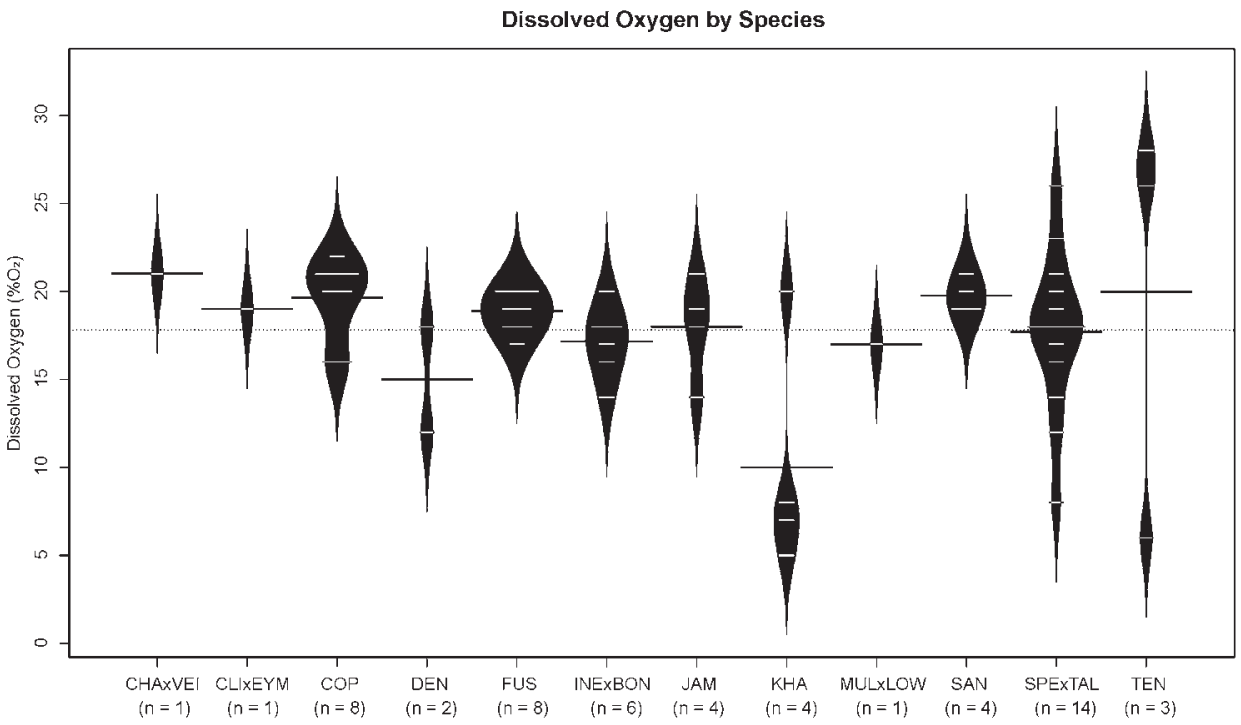

Figure 2: Beanplot showing results of oxygen measurements in 12 Nepenthes species and hybrids in the HortPark glasshouse. $\mathrm{CHAxVEI}=N$. chaniana $\times$ veitchii, CLIXEYM $=N$. clipeata $\times$ eymae, $\mathrm{COP}=N$. copelandii, $\mathrm{DEN}=N$. densiflora, $\mathrm{FUS}=N$. fusca, INExBON = $N$. inermis $\times$ bongso, JAM $=N$. jamban, $\mathrm{KHA}=N$. khasiana, $\mathrm{MUL} \times \mathrm{LOW}=N$. muluensis $\times$ lowii, SAN $=N$. sanguinea, SPExTAL $=N$. spectabilis $\times$ talangensis, $\mathrm{TEN}=N$. tentaculata . Please note that names are based on 2014 taxonomic classifications (e.g. N. fusca is likely now $N$. dactylifera). Sample sizes for each species given below in parentheses. In the beanplot, thin white lines represent individual samples (length proportional to number of samples at a given DO) and thick black bar represents mean DO for that species. Dotted line indicates overall mean. 
N. fusca

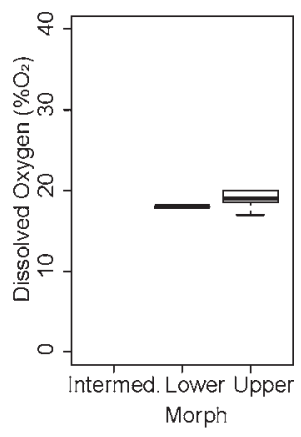

N. sanguinea

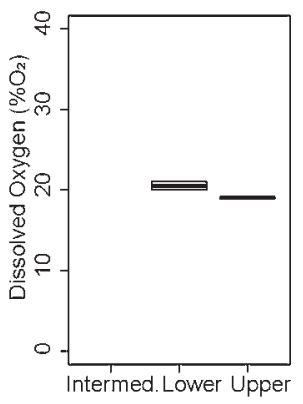

N. inermis $x$ bongso

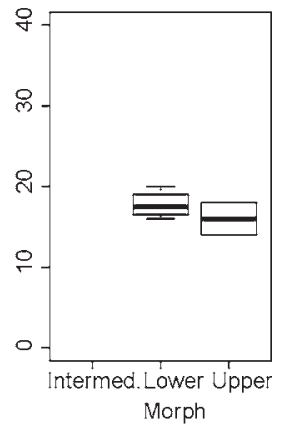

N. spectabilis $x$ talangensis

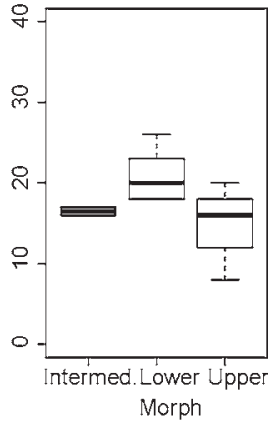

N. jamban

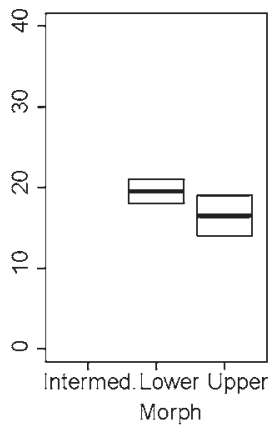

N. tentaculata

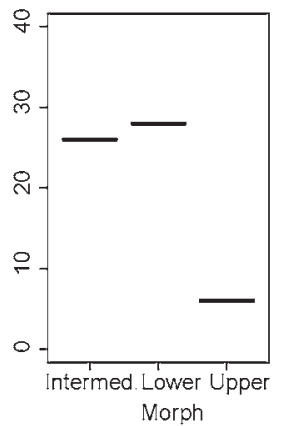

Figure 3: Boxplots of data from the 2014 HortPark glasshouse study, broken down by pitcher morph (upper, lower, or intermediate) for applicable species/hybrids.

datapoints for multiple $N$. spectabilis $\times$ talangensis plants containing upper, lower, and intermediate pitcher morphs, and the difference in means between upper and lower pitchers was significant in this case ( $\mathrm{t}$-test, $\mathrm{t}=-2.58, \mathrm{p}=0.03$ ). While I only had one sample of each morph from $N$. tentaculata, the same trend can be found in that species as well (Fig. 3) - in both cases, lower pitchers have greater DO levels than upper pitchers, and the intermediate morphs notably fall somewhere in between. Note that most of the points that fall below 15\% in Figure 2 are from upper pitchers (except one from $N$. densiflora and two from $N$. khasiana). Upper pitchers are necessarily younger than lower pitchers on the same plant, so I believe this trend may again indicate that more newly opened pitchers decrease their fluid DO.

Measuring DO in fluid from unopened pitchers of wild $N$. gracilis provided further support for the idea that younger pitchers normally have decreased DO levels. All five fluid samples were fairly hypoxic: $2.88 \mathrm{mg} / \mathrm{L}, 4.33 \mathrm{mg} / \mathrm{L}, 4.33 \mathrm{mg} / \mathrm{L}, 3.11 \mathrm{mg} / \mathrm{L}$, and $3.77 \mathrm{mg} / \mathrm{L}$, for a mean of $3.68 \mathrm{mg} / \mathrm{L}$. This unopened $N$. gracilis fluid was not anoxic like I had previously observed in newly-opened $N$. maxima and $N$. albomarginata in the growth chamber, but still comparably hypoxic to the newlyopened $N$. ampullaria. Perhaps Nepenthes pitcher fluid in unopened/newly-opened pitchers is generally hypoxic, but different species vary in their minimum levels.

A possible mechanism that can explain how pitchers in their earliest stages of development deoxygenate their fluid is due to new pitchers releasing large amounts of gaseous carbon dioxide (Baby et al. 2017), this would flush oxygen out of the fluid; this process may cease as the pitchers mature, possibly giving way to increased input of oxygen from photosynthesis. 


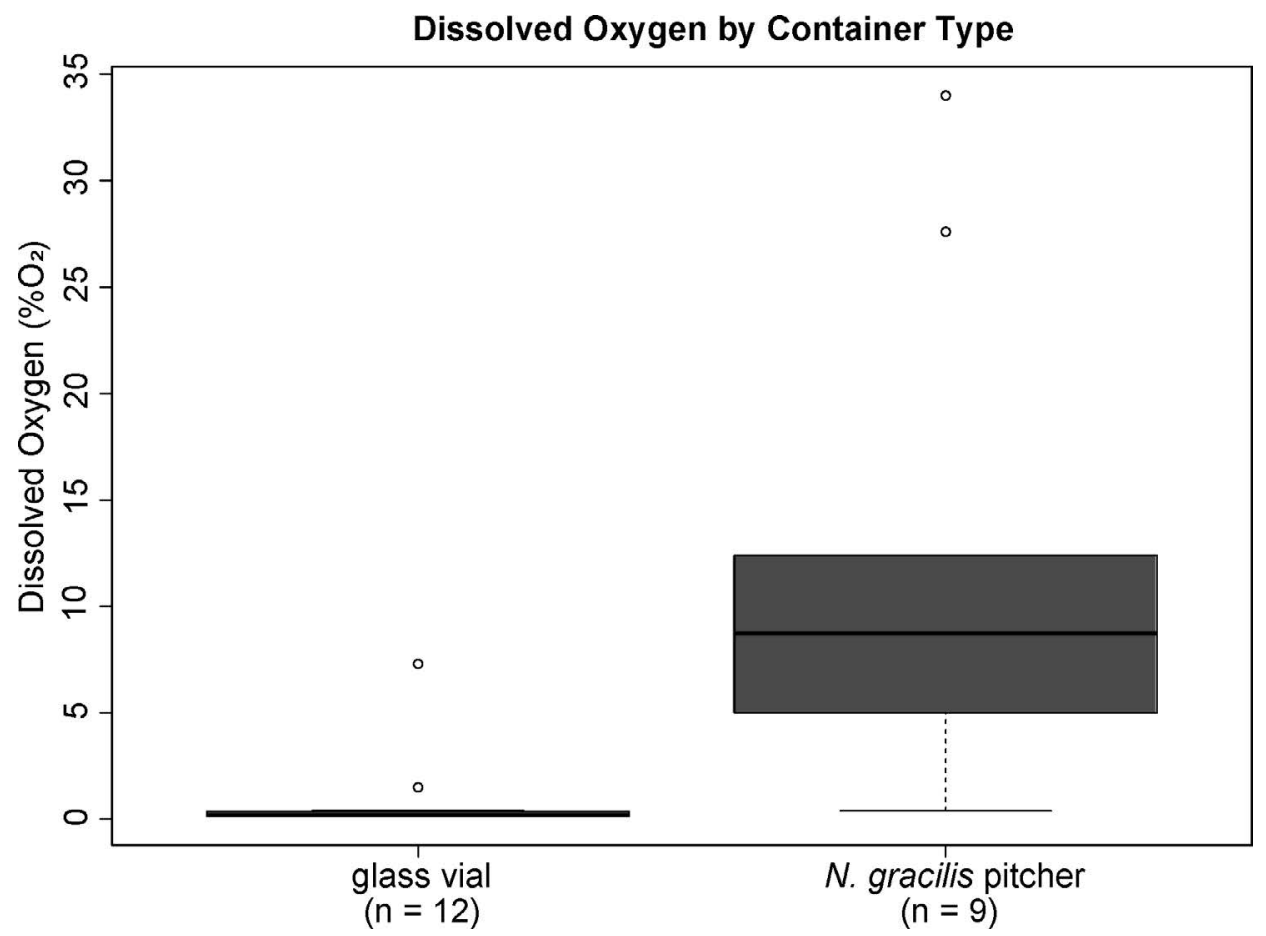

Figure 4: Results of the 2016 Raffles Institute greenhouse experiment, dissolved oxygen levels of pitcher fluid in glass vials and pitchers 18 hours after adding mealworm segment and insect inquiline treatments.

My most direct evidence of active oxygenation in healthy mature pitchers comes from the 2016 greenhouse experiment, where I had natural pitcher fluids with prey and inquilines (Fig. 4). I found significantly higher DO levels in pitchers than in glass vials (Kruskal-Wallis chi-squared $=12.16, \mathrm{p}$ $=0.0005$ ) showing both how quickly inquiline respiration can lead to severely hypoxic pitcher fluid in physiologically inactive containers (final $\mathrm{O}_{2}$ levels falling mostly between $0.11 \%$ and $0.42 \%$, where atmospheric oxygen in the greenhouse was $22.8 \%$ ), and suggesting that the plants keep fluid oxygenated with photosynthesis that outpaces inquiline respiration. There were no significant differences in DO levels between the different insect inquiline treatments (Kruskal-Wallis test, $p$ > $0.05)$, suggesting that the bulk of the oxygen consumption that occurred was due more to microbial respiration rather than insect respiration (though evaporation may also have played some role in oxygen depletion).

The near-anoxic conditions in the glass vials were sufficient to lead to death of the larvae, so pitcher oxygenation likely has fitness consequences for inquilines in the wild, allowing larvae to occupy fluids with substantial microbial populations that would be otherwise uninhabitable if not for oxygenation by the host plant. On the other hand, while hypoxic conditions in pitchers prior to opening may not be of consequence to inquilines when entry is impossible anyway, the persistent removal of oxygen that continues during the first few days after opening would be consequential to pitcher inhabitants. Perhaps these hypoxic conditions might benefit the plant by discouraging insect colonization too early on. Larval inquilines can act either as mutualists or parasites (Scharmann et al. 2013; Leong et al. 2018, 2019); perhaps larvae can be more beneficial when pitchers are mature 
and full of prey, but when the pitcher is still new with limited prey, a growing larva could more easily steal more nutrients than it releases.

\section{Conclusions}

Nepenthes appear to be capable of actively oxygenating the fluid within their pitchers, analogous to what was already known for Sarracenia. Unexpectedly, I also found that unopened pitchers and pitchers in the earliest stages post-opening may actively decrease their DO levels (reaching total anoxia, at least in N. maxima and $N$. albomarginata). Oxygen regulation possibly varies by species, but the difference between pitchers of different ages seems more pronounced than interspecific differences. Understanding how fluid properties like DO are regulated by the plants has implications for understanding how the plant interacts with its symbionts (Adlassnig et al. 2011; Bittleston 2018; Gaume et al. 2019; Gilbert et al. 2020). Interspecific differences in DO regulation could very well contribute to the ability of pitchers to act as filters to shape what insects and microbes live within them.

Acknowledgements: I thank Sasha Johnson-Freyd for assistance with micro-Winkler titrations in 2013, Dr. Shawn Lum for his general support and advice in Singapore, greenhouse manager Patrick Hayes and the staff of the HortPark Nepenthes nursery (e.g., Desmond) for allowing and aiding my data collection in 2014, and Dr. Jeffrey Lee for his generous collaboration at the Raffles Institute in 2016. I also thank Dr. N. Michele Holbrook and Dr. Fulton Rockwell for helpful conversations and help with operating and troubleshooting oxygen optrodes. Additionally, I thank Drs. Naomi Pierce, Jon Sanders, Leonora Bittleston, Aaron Ellison, and Peter Girguis for helpful conversations during these exploratory studies. The author was supported by a graduate research fellowship from the Department of Organismic and Evolutionary Biology at Harvard University, a Miyata Grant, and a Putnam Expedition Grant; work in Singapore natural parks was made possible by research permits NP/RP15-147 and NP/RP13-017-1.

\section{References}

Adamec, L. 2010. Ecophysiological look at organ respiration in carnivorous plants: a review. Cell respiration and cell survival: processes, types and effects. New York: Nova Science Publishers, Inc: $225-235$.

Adlassnig, W., Peroutka, M., and Lendl, T. 2011. Traps of carnivorous pitcher plants as a habitat: composition of the fluid, biodiversity and mutualistic activities. Annals of Botany 107: 181-194.

Baby, S., Johnson, A.J., Zachariah, E.J., and Hussain, A.A. 2017. Nepenthes pitchers are $\mathrm{CO}_{2}-$ enriched cavities, emit $\mathrm{CO}_{2}$ to attract preys. Scientific Reports 7, 11281. https://doi.org/10.1038/ s41598-017-11414-7.

Bates, D., Mächler, M., Bolker, B., and Walker, S. 2015. Fitting linear mixed-effects models using lme4. J. Statistical Software 67(1): 1-48. https://www.jstatsoft.org/v067/i01

Bittleston, L. 2018. Commensals of Nepenthes pitchers. Carnivorous Plants: Physiology, Ecology, and Evolution. Oxford University Press. DOI: https://doi.org/10.1093/oso/9780198779841.00323.

Bradshaw, W.E. 1983. Interaction between the mosquito Wyeomyia smithii, the midge Metriocnemus knabi, and their carnivorous host Sarracenia purpurea. In: J.H. Frank and L.P. Lounibos (eds.), Phytotelmata: Terrestrial Plants as Hosts for Aquatic Insect Communities. Plexus, Medford, NJ.: 161-189.

Cameron, C., Donald, G., and Paterson, C. 1977. Oxygen-fauna relationships in the pitcher plant Sarracenia purpurea L. with reference to the chironomid Metriocnemus knabi Coq. Canadian Journal of Zoology 55: 2018-2023. 
Gaume, L., Bazile, V., Boussès, P., Le Moguédec, G., and Marshall, D.J. 2019. The biotic and abiotic drivers of "living"diversity in the deadly traps of Nepenthes pitcher plants. Biodiversity and Conservation 28: 345-362.

Gilbert, K.J., Bittleston, L.S., Tong, W., and Pierce, N.E. 2020. Tropical pitcher plants (Nepenthes) act as ecological filters by altering properties of their fluid microenvironments. Scientific Reports 10, 4431. https://doi.org/10.1038/s41598-020-61193-x.

Heard, S.B. 1994. Pitcher-plant midges and mosquitoes: a processing chain commensalism. Ecology $75: 1647-1660$.

Joel, D.M., and Gepstein, S. 1985. Chloroplasts in the epidermis of Sarracenia (the American pitcher plant) and their possible role in carnivory-An immunocytochemical approach. Physiologia Plantarum 63: 71-75.

Kitching, R. 2001. Food webs in phytotelmata: "bottom-up" and "top-down" explanations for community structure. Annual Review of Entomology 46: 729-760.

Laessle, A.M. 1961. A micro-limnological study of Jamaican bromeliads. Ecology 42: 499-517.

Leong, F.W.S., Lam, W.N., and Tan, H.T.W. 2018. A dipteran larva-pitcher plant digestive mutualism is dependent on prey resource digestibility. Oecologia 188: 813-820.

Leong, F.W.S., Lam, W.N., and Tan, H.T.W. 2019. Digestive mutualism in a pitcher plant supports the monotonic rather than hump-shaped stress-gradient hypothesis model. Oecologia 190: 523534.

Moran, J.A., Clarke, C.M., and Hawkins, B.J. 2003. From carnivore to detritivore? Isotopic evidence for leaf litter utilization by the tropical pitcher plant Nepenthes ampullaria. International Journal of Plant Sciences 164: 635-639.

Moran, J.A., Hawkins, B.J., Gowen, B.E., and Robbins, S.L. 2010. Ion fluxes across the pitcher walls of three Bornean Nepenthes pitcher plant species: flux rates and gland distribution patterns reflect nitrogen sequestration strategies. Journal of Experimental Botany 61: 1365-1374.

Pavlovič, A., Masarovičová, E., and Hudák, J. 2007. Carnivorous syndrome in Asian pitcher plants of the genus Nepenthes. Annals of Botany 100: 527-536.

Pavlovič, A., Singerová, L., Demko, V., and Hudák, J. 2009. Feeding enhances photosynthetic efficiency in the carnivorous pitcher plant Nepenthes talangensis. Annals of Botany 104(2): 307314.

R Core Team. 2013. R: A Language and Environment for Statistical Computing. R Foundation for Statistical Computing, Vienna. http://www.R-project.org/.

Scharmann, M., Thornham, D.G., Grafe, T.U., and Federle, W. 2013. A novel type of nutritional antplant interaction: ant partners of carnivorous pitcher plants prevent nutrient export by dipteran pitcher infauna. PloS ONE 8(5): e63556. https://doi.org/10.1371/journal.pone.0063556.

Shriwastav, A., Sudarsan, G., Bose, P., and Tare., V. 2010. Modification of Winkler's method for determination of dissolved oxygen concentration in small sample volumes. Analytical Methods 2: $1618-1622$. 